\title{
Borg Category-Ratio 10 Scale Score 11 Point Scale
}

National Cancer Institute

\section{Source}

National Cancer Institute. Borg Category-Ratio 10 Scale Score 11 Point Scale. NCI

Thesaurus. Code C122944.

A scale for the subjective scoring of perceived exertion that ranges from 0: Nothing at all to 10: Maximal. 